\title{
EKSISTENSI PARTAI INDONESIA RAYA (PARINDRA) DI KALIMANTAN SELATAN, 1935- 1942
}

\author{
THE EXISTENCE OF INDONESIA RAYA PARTY (PARINDRA) \\ IN SOUTH KALIMANTAN, 1935-1942
}

\author{
Wajidi \\ Balitbangda Provinsi Kalimantan Selatan \\ Jalan Aneka Tambang-Trikora, \\ Kompleks Perkantoran Pemerintah Provinsi Kalimantan Selatan, Banjarbaru \\ email:wajidi.amberi@gmail.com
}

Naskah Diterima: 8 Januari $2015 \quad$ Naskah Direvisi:16 Februari $2015 \quad$ Naskah Disetujui:23 Februari 2015

\begin{abstract}
Abstrak
Parindra merupakan organisasi pergerakan berpusat di Jawa yang mempunyai cabang organisasi di Kalimantan Selatan. Peranannya di Kalimantan Selatan belum banyak dipublikasikan. Atas dasar alasan itulah, maka kajian ini bertujuan untuk: (1) mengetahui persebaran organisasi Parindra di Kalimantan Selatan; (2) mengetahui perjuangan Parindra di Kalimantan Selatan; (3) mengetahui tindakan Pemerintah Hindia Belanda terhadap Parindra di Kalimantan Selatan. Penelitian ini merupakan penelitian sejarah (historical research) dengan menggunakan sebagian besar data primer yakni memoar para pelaku sejarah dari anggota perintis kemerdekaan. Hasil kajian menunjukkan bahwa asal mula Parindra di Kalimantan Selatan adalah organisasi Persatuan Bangsa Indonesia (PBI) yang dibentuk pada tahun 1930. Karena berfusinya PBI dengan Budi Utomo dan organisasi lainnya di pulau Jawa menjadi Partai Indonesia Raya (Parindra) di tahun 1935 maka dengan sendirinya PBI di Kalimantan Selatan menjadi Parindra. Perjuangan Parindra di Kalimantan Selatan di antaranya: duduk dalam keanggotaan dewan legislatif (Raad), mendirikan Rukun Tani, Koperasi, Rukun Pelayaran Indonesia (Roepelin), dan Lumbung Padi, Mendirikan organisasi Keputrian, Kepanduan Surya Wirawan, dan Sekolah Parindra, menulis artikel politik dan mengeluarkan mosi menentang peraturan kerja paksa (erakan, rodi). Pemerintah Hindia Belanda menghadapi perjuangan Parindra dengan cara melakukan tindakan pengawasan, pelarangan, dan pembubaran rapat serta penangkapan dan pemenjaraan aktivis Parindra di Kalimantan Selatan.
\end{abstract}

Kata kunci: Parindra, Kalimantan Selatan, Pemerintah Hindia Belanda.

\begin{abstract}
Parindra is a Java-based movement organizations that have branch organization in South Kalimantan. Its role in South Kalimantan has not been widely publicized. Based on that reasons, the study aims are to: (1) determine the distribution of Parindra organization in South Kalimantan; (2) determine Parindra struggle in South Kalimantan; (3) determine the action of Dutch East Indies government against Parindra in South Kalimantan. This research is the historical research by using most of the primary data that the perpetrators of historical memoirs of pioneering independence members. The results show that the origin of Parindra in South Kalimantan is the organization Persatuan Bangsa Indonesia (PBI) was formed in 1930. Since the fusion of PBI with Budi Utomo and other organizations on the island of Java, Indonesia Raya became a Party (Parindra) in 1935 then by itself PBI in South Kalimantan into Parindra. Parindra struggle in South Kalimantan include: sitting in the membership of the legislative council (Raad), established the Pillars of Farmers, cooperatives, Pillars Shipping Indonesia (Roepelin), and Lumbung Padi, Establishing keputrian organization, Scouting Surya Wirawan, and School Parindra, write political articles and issued a motion against the labor regulations (erakan, forced labor). Dutch East Indies government facing Parindra movement with perform
\end{abstract}


acts of supervision, prohibition and dissolution of the meeting as well as the arrest and imprisonment of activists Parindra in South Kalimantan.

Keywords: Parindra, south Kalimantan, Dutch East Indies.

\section{A. PENDAHULUAN}

Paruh pertama abad ke-20 merupakan puncak dari kolonialisme dan imperialisme di Indonesia. Pada saat bersamaan, awal abad ke-20 juga dikenang sebagai masa tumbuh dan berkembangnya nasionalisme.

Kalimantan Selatan (termasuk Kalimantan Tengah dan Timur sekarang) merupakan bagian dari konstelasi pergerakan kebangsaan Indonesia pada waktu itu. Di daerah ini yang pada masa pergerakan kebangsaan disebut Keresidenan Afdeling Selatan dan Timur Borneo atau Residentie Zuider en Oosterafdeling van Borneo dengan ibu kota Banjarmasin (ANRI, 1986: iv) berkembang berbagai organisasi yang berlingkup lokal, regional, maupun nasional. Atau dari yang semula bersifat kedaerahan dan bergerak di bidang sosial, ekonomi, dan keagamaan, terus berkembang ke arah kebangsaan melalui pergerakan politik praktis dengan tujuan meraih kemerdekaan. Perasaan kebangsaan yang sebenarnya lahir dari kondisi masyarakat itu sendiri sebagai dampak dari penjajahan, seperti penindasan dan perlakuan diskriminatif, munculnya sistem ekonomi modern, praktik kerja paksa (rodi) atau erakan, telah mendorong tumbuhnya kesadaran akan harga diri yang semakin menguat dengan masuknya pengaruh pergerakan kebangsaan yang tumbuh di Jawa dan menyebar luas hingga sampai ke daerah ini.

Penetrasi kebudayaan Barat yang sangat kuat pengaruhnya terhadap tumbuhnya pergerakan kebangsaan di daerah ini adalah penetrasi di bidang pendidikan berupa pengajaran secara Barat yang melahirkan kaum cendekiawan, terutama "elite nasional" (elite sekuler maupun elite religius), yakni para lulusan sekolah partikelir atau sekolah agama yang berjuang untuk kemajuan dan kesejahteraan bangsanya.

Lancarnya hubungan kapal laut antara Banjarmasin dan kota-kota di pantai utara Pulau Jawa, berdampak terhadap lancarnya komunikasi dan informasi antara sebagian penduduk Kalimantan Selatan dan Jawa. Berkat adanya pengalaman, pengetahuan dan hubungan dengan dunia luar dan melihat kemajuan pergerakan di daerah lain, baik secara langsung maupun melalui pemberitaan pers, maka para pedagang yang kembali dari Jawa ke kampung halamannya turut menjadi pelopor atau penggerak organisasi pergerakan kebangsaan di Kalimantan Selatan. Mereka membawa paham pergerakan rakyat yang tumbuh di Jawa atau mendirikan cabang organisasi di Kalimantan Selatan, salah satunya adalah Parindra. Yang menjadi permasalahan adalah bagaimana eksistensi organisasi Partai Indonesia Raya (Parindra) di Kalimantan Selatan? Oleh karena itulah kajian ini dimaksudkan untuk mengetahui: (1) persebaran organisasi Parindra di Kalimantan Selatan; (2) perjuangan Parindra di Kalimantan Selatan; (3) tindakan Pemerintah Hindia Belanda terhadap Parindra di Kalimantan Selatan.

\section{B. METODE PENELITIAN}

Tulisan ini disusun berdasarkan metode penelitian sejarah (historical research) dengan mengikuti langkahlangkah yakni heuristik, kritik, interpretasi dan historiografi (Louis Gottschalk, 1985 dan Helius Sjamsuddin, 2012). Metode ini pada prinsipnya merupakan suatu proses untuk menguji dan menganalisis secara kritis sumber, rekaman dan peninggalan masa lalu dengan merekonstruksi berdasarkan data yang diperoleh dengan menempuh proses historiografi (Gottschalk, 1985:32). 
Kajian ini lebih menitikberatkan pada studi bahan dokumen yakni berbagai sumber sezaman (sumber primer) berupa manuskrip atau arsip, di samping sumber sekunder berupa buku-buku, skripsi, jurnal dan lain-lain.

Sumber primer terpenting adalah memoar para pejuang perintis kemerdekaan dan foto-foto asli maupun fotokopi yang diperoleh dari para ahli warisnya, seperti koleksi Yurliani Johansyah, Abdul Muis, Artum Artha, dan keluarga almarhum Achmad Darmawie (Ketua Cabang Persatuan Perintis Kemerdekaan) di Banjarmasin.

Sebagian besar memoar yang terkumpul dan dipergunakan dalam tulisan ini memang sengaja disusun pelaku sejarah sebagai bahan kelengkapan permohonan atau usulan untuk mendapatkan pengakuan dari pemerintah sebagai pejuang perintis kemerdekaan.

Lingkup analisis studi adalah kiprah organisasi Parindra di Kalimantan Selatan yang menyangkut persebaran organisasi, perjuangannya, dan tindakan Pemerintah Hindia Belanda terhadap Parindra di Kalimantan Selatan pada rentang waktu 1935 sampai dengan 1942. Penetapan tahun 1935 diambil karena pada tahun itulah berdiri organisasi Parindra dan berakhir pada tahun 1942 menyusul kedatangan tentara pendudukan Jepang di Kalimantan Selatan.

Lingkup spasial dalam kajian ini dibatasi hanya pada afdeling Selatan dalam wilayah Keresidenan Afdeling Selatan dan Timur Borneo yang di kemudian hari menurut Staatsblaad 1945 Nomor 64 dikenal sebagai Keresidenan Borneo Selatan (Residentie Zuider Afdeling van Borneo) dengan ibu kotanya Banjarmasin yang wilayahnya sekarang meliputi dua provinsi yakni Provinsi Kalimantan Selatan dan Kalimantan Tengah (Pemda Tk. I Kalsel, 1990:4).

\section{HASIL DAN BAHASAN \\ 1. Persebaran Parindra di Kalimantan Selatan}

Parindra didirikan oleh dr. Sutomo dan kawan-kawan pada tahun 1935 di Surabaya dan merupakan fusi dari partaipartai politik, antara lain: Budi Utomo, Paguyuban Pasundan, Serikat Betawi, Serikat Ambon, Serikat Minahasa, Persatuan Bangsa Indonesia (PBI), dan Sumateranen Bond. Di dalam Parindra-lah golongan cerdik-cendekiawan priyayi Jawa yang diwakili PBI dan golongan birokratis konservatif priyayi Jawa yang diwakili feodal Budi Utomo dapat digabungkan dengan serasi ke dalam satu barisan dan mampu bekerja bersama secara politik (Scherer, 1985:222). Parindra merupakan partai politik yang berdasarkan nasionalisme Indonesia Raya dan bertujuan Indonesia Mulya dan Sempurna.

Di Kalimantan Selatan, pada mulanya Parindra bernama Persatuan Bangsa Indonesia (PBI). Organisasi PBI dibentuk pada tahun 1930, dipelopori oleh Merah Johansyah dan Masri, dengan jumlah anggota tidak lebih dari 15 orang (Darmawie, 1981:4). Mereka bergerak secara sembunyi-sembunyi karena kuatir ditangkap polisi kolonial Belanda atau PID (Politieke Inlichtingen Dienst).

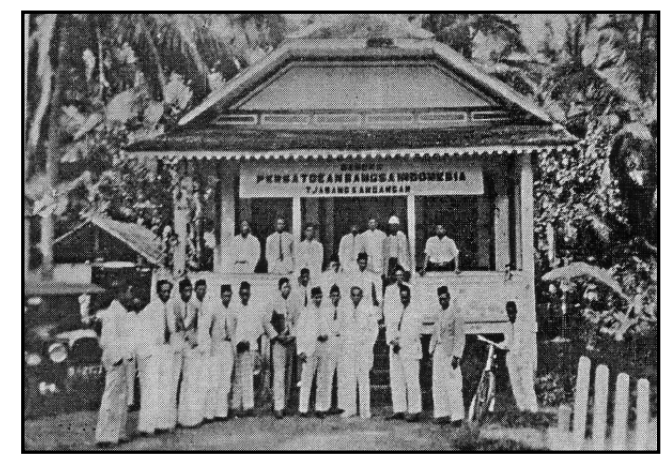

Gambar 1. Persatuan Bangsa Indonesia (PBI) Cabang Kandangan.

Sumber: Koleksi Yurliani Johansyah.

Pada tanggal 14 Mei 1932, PBI Banjarmasin diakui sebagai cabang oleh Pengurus Besar PBI. Dari Banjarmasin, PBI berkembang ke daerah lainnya sehingga mempunyai cabang-cabang seperti di Kandangan, Barabai dan 
Amuntai. Organisasi PBI digerakkan oleh kaum intelek, terutama guru-guru.

Di samping itu, dibentuk pula Surya Wirawan sebagai organisasi kepemudaan dan kepanduan dari PBI. Surya Wirawan cabang Banjarmasin diketuai oleh A. Ibrahim dengan wakil ketua Achmad Darmawie sekaligus sebagai sekretaris. Organisasi kepemudaan ini diberi latihan kepanduan, kursus kepemimpinan, disiplin partai, kebangsaan, dan patriotisme berdasarkan asas kepartaian PBI yakni Kebenaran, Keadilan, Kesucian, Kecintaan, dan Pengorbanan (Darmawie, 1981:5). Ketika terjadi fusi pembentukan Parindra pada tahun 1935, Surya Wirawan menjadi organisasi yang dikelola oleh Parindra.

Tatkala PBI berdiri di Kandangan pada tahun 1933, seorang guru di Kandangan, yakni Haji Muhammad Hapip, meminjamkan sebuah rumah di Jalan Masjid untuk kegiatan PBI dan untuk Perguruan Rakyat, yang di kemudian hari menjadi Perguruan Rakyat Parindra Kandangan (Artha, 1984: tanpa halaman).

Setelah kejadian Pemberontakan awak Kapal Tujuh (Zeven Provincien) tersiar di Banjarmasin, suasana politik menjadi agak keruh, karena Belanda mencurigai PBI akan mengadakan aksi demonstrasi. Pihak kolonial Belanda memang merahasiakan pemberontakan itu, akan tetapi masyarakat ternyata mengetahuinya.

Pada tahun 1934, PBI cabang Barabai berdiri, dipimpin oleh $\mathrm{H}$. Ali Baderun (ketua), H. Kadri (wakil ketua), A. Azis Mansyur (sekretaris), dan Zakaria (bendahara). Mereka melakukan kursus atau propaganda partai ke kampungkampung sekali seminggu, mengadakan sekolah buta huruf untuk orang tua, mendirikan rukun kematian, mendirikan sekolah swasta untuk anak-anak, menjalankan les derma kepada para anggota untuk kepentingan partai, dan propaganda lainnya secara tidak langsung, seperti pada acara perkawinan, selamatan, dan lain-lain (Alibasah, 1981: tanpa halaman).

Setelah berfusinya PBI dengan Budi Utomo dan organisasi lainnya menjadi Parindra pada tahun 1935, perkembangan politik di Kalimantan Selatan semakin meningkat. Dalam geraknya di Kalimantan Selatan, Parindra berkembang ke berbagai kota seperti Kuala Kapuas, Sampit, Kandangan, Barabai, Amuntai, Haruai, Pagatan, dan Kotabaru, bahkan sampai ke daerah Kalimantan Timur (Samarinda dan Sangkulirang). Perkembangan yang pesat, menjadikan organisasi Parindra satusatunya partai politik terbesar yang ada saat itu di daerah ini.

Di Kuala Kapuas, cabang Parindra dibentuk pada tanggal 23 Juli 1939 oleh Komisaris Pengurus Besar Parindra Hadhariyah M di gedung HBS Kampung Hampatung Kuala Kapuas, dipimpin oleh W. Sandan sebagai ketua dan A. Rasyid sebagai penulis/sekretaris (Darmawie, 1981:7; Arief, 1981:14).

Di Kandangan, Parindra berdiri pada tahun 1935. Pemimpin pertama adalah Muhammad Abdul Husein (Kepala Sekolah HIS). Pemimpin kedua Muhammad Hanafiah (Wakil Kepala Sekolah HIS). Setelah keduanya dipindahkan ke Jawa dan Madura, pelanjutnya adalah Ahmad Barmawi, Haji Muhammad Syukeri dan Haji Muhammad Syamsi Rais.

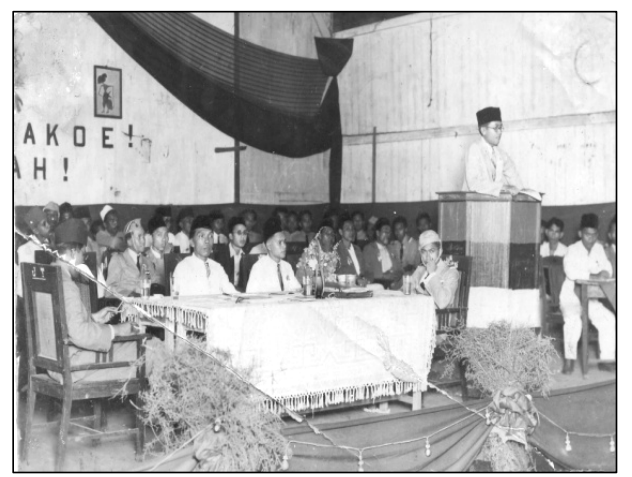

Gambar 2. Suasana rapat pembentukan pengurus Parindra cabang Barabai, tahun 1939. Sumber: Koleksi Abdul Muis 
Di Barabai, Parindra berdiri pada tahun 1936. Pengurus pertama diketuai oleh H. Ali Baderun dan bermarkas di Gedung Parindra berukuran 15 x $20 \mathrm{~m}$ yang berlokasi di Bulau, yang sekarang menjadi Jalan Sarigading, Barabai. Pembangunannya dilakukan secara gotong royong dengan menjalankan les derma di masyarakat dan dengan cara memungut iuran kepada anggota (Uhuk, 1981: 8).

Parindra berusaha memperbaiki penghidupan rakyat dengan memberikan pertolongan dan pimpinan yang nyata, dengan mendirikan badan-badan koperasi, rukun tani, bank rakyat, pelayaran dan perdagangan. Parindra juga mengadakan diskusi atau kursus-kursus seperti kursus administrasi, kepemimpinan, dan kursus pidato. Karena usahanya itulah, maka jumlah anggotanya cepat bertambah dengan cabang-cabang dan ranting-ranting baru yang bermunculan di desa-desa.

Di Kampung Hantakan yang jauhnya sekitar $9 \mathrm{~km}$ dari kota Barabai, dibentuk pengurus ranting/seksi Parindra Hantakan pada tanggal 1 Juni 1939. Pembentukan pengurus dihadiri oleh sekitar 500 orang Parindrist dari berbagai pelosok, seperti dari Birayang, Pantai Hambawang, Aluan Sumur, Pelajau, dan Mahang. Di sini dilaksanakan rapat terbuka (openbare vergadering) dengan penyampaian pidato yang berapi-api (Arief, 1981: 12).

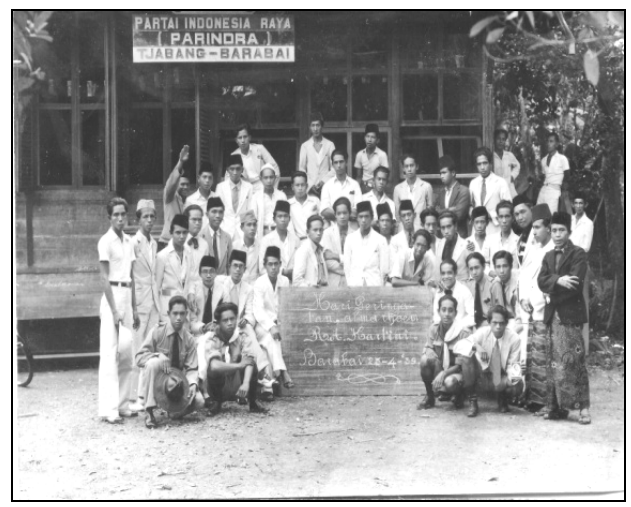

Gambar 3. Markas Parindra Cabang Barabai. Tampak papan hitam bertulisan "Hari
Peringatan Almarhoem R.A. Kartini, Barabai 23-4-“39”.

Sumber: Koleksi Abdul Muis.

Di Desa Karatau, Ranting PBI berubah menjadi Ranting Parindra diketuai oleh Alibasah. Pada tahun 1937, Alibasah ditangkap oleh PID dan ditahan selama 21 hari, karena mengadakan rapat tertutup di Karatau dan tidak mendapat izin dari PID (Alibasah, 1981: tanpa halaman).

Di Barabai, Parindra pernah mengadakan rapat terbuka (openbar) di los Getah, pasar Barabai. Pada saat itulah tampil seorang wanita dari Kandangan bernama Siti Syahrijat memberanikan diri berpidato di depan khalayak ramai. Ia menjadi seorang wanita yang tidak kenal takut berpidato dengan lantang di muka umum pada masa penjajahan. Isi pidatonya bertujuan membangun semangat kaum perempuan, membangkitkan kegairahan dan menyadarkan kaum ibu serta mengajak mereka agar tidak hanya menjadi ratu dapur yang semata-mata memasak dan memelihara anak, akan tetapi perempuan juga harus bangkit dan mengikuti jejak langkah kaum pria dalam menentukan langkah nasib bangsa di kemudian hari, sesuai dengan kemampuannya sebagai seorang perempuan (Uhuk, 1981: 9).

\section{Perjuangan Parindra Dalam Menghadapi Pemerintah Hindia Belanda}

Perjuangan Parindra dalam menghadapi politik Pemerintah Hindia Belanda meliputi berbagai bidang dan kesempatan. Di bidang politik, Parindra berusaha duduk dalam keanggotaan RaadRaad (Dewan), seperti Volksraad (Dewan Rakyat) di pusat, Provinciale Raad (Dewan Provinsi) di daerah (Kalimantan Selatan), Banjar Raad, Gemeenteraad (Dewan Gemeente), dan Raad-Raad lokal lainnya.

Menurut L.M. Sitorus (1951:52), organisasi Parindra tidak secara prinsipil menganut asas politik non co atau co, sehingga sepak terjangnya keluar tampak seperti cooperator dan kadang-kadang 
seperti non-cooperator. Parindra tidak menolak duduk dalam dewan-dewan bentukan pemerintah kolonial, tetapi bila perlu atau jika usulnya tidak diterima oleh pemerintah kolonial, mereka meninggalkan dewan-dewan tersebut dan menjalankan apa yang disebut dengan incidentele atau utilistche non-cooperatie (memanfaatkan sikap non-kooperatif) selama waktu yang ditentukan oleh partai.

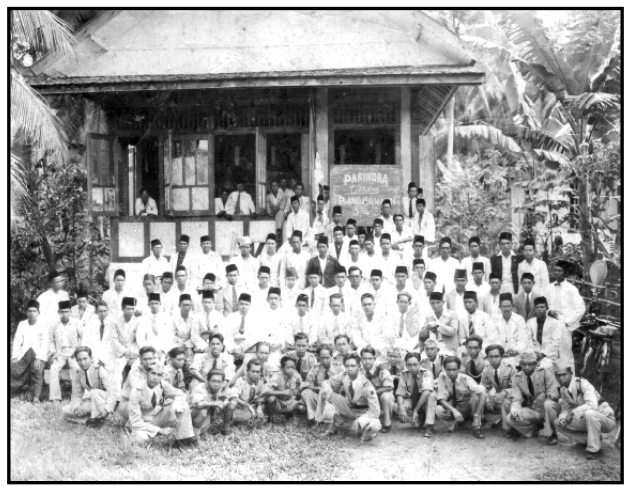

Gambar 4. Gedung Parindra Cabang Banjarmasin, Jalan Ulin/Jalan Pasar Lama, 3 April 1938

Sumber: Koleksi Achmad Darmawie

Meskipun Parinda menganut asas politik kooperatif, organisasi ini tetap bertujuan untuk mencapai Indonesia merdeka. Sebagaimana dikatakan oleh Mohammad Husni Thamrin dalam pidatonya, bahwa nasionalis kooperatif dan nonkooperatif memiliki satu tujuan bersama yang sama-sama yakin pada Indonesia Merdeka (Abdullah (ed.), 2013: 148).

Duduknya anggota Parindra dalam Banjar Raad, mempunyai tujuan tertentu, yaitu: (1) Untuk menyampaikan suara rakyat secara legal; (2) Memberikan saran agar dalam mengatur pemerintahan, banyak memberikan keuntungan kepada rakyat; (3) Mencoba melakukan oposisi secara sehat; (4) Memperlihatkan kepada pemerintah kolonial Belanda bahwa bangsa Indonesia sanggup memerintah (Sjarifuddin, 1974: 65).
Anggota Parindra yang menjadi anggota Raad-Raad itu, diperankan untuk dua tujuan:

1. Kepada pemerintah kolonial Belanda menyampaikan apa yang menjadi tuntutan Parindra.

2. Kepada rakyat, tokoh-tokoh inilah yang menjelaskan tentang sikap dan sepak terjang pemerintahan Hindia Belanda, seperti melalui rapat-rapat partai, atau kursus-kursus. Dengan demikian, anggota partai makin memahami dan mengerti masalahmasalah politik (Sjarifuddin, 1974: 65).

Dalam rangka memperluas perkembangan partai, terutama Parindra cabang Banjarmasin, sekaligus untuk mempertebal semangat nasionalisme dan patriotisme para anggota partai, maka diundanglah para pemimpin pusat/Pengurus Besar Parindra ke Kalimantan Selatan, yakni Mohammad Husni Thamrin, R. Sukardjo Wiryopranoto, R. Sunyoto (Hadhariyah, 1981:8 dan Darmawie, 1981: 6).

Selain di Banjarmasin, Mohammad Husni Thamrin yang juga seorang anggota Volksraad berkunjung pula ke hulu Sungai Kandangan, Barabai, Amuntai untuk melakukan pertemuan dan rapat-rapat umum. Di Barabai, Mohammad Husni Thamrin berkesempatan melakukan pelantikan Ranting Parindra Birayang menjadi Cabang Parindra Birayang yang berlangsung pada bulan Oktober 1937.

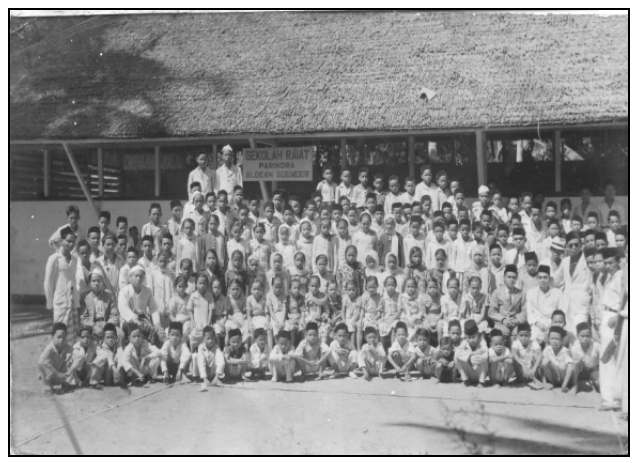

Gambar 5. "Sekolah Ra'jat Parindra Aloean Soemoer", Barabai 
Sumber: Koleksi Abdul Muis

Parindra Cabang Birayang aktif melaksanakan program perjuangan, seperti mengadakan kursus dan mendirikan sekolah Neutralschool. Guru-gurunya antara lain H.M. Arif, Sunaryo, dan M.Y.H.W. Puloakan (Busri, tanpa tahun: tanpa halaman).

Tokoh lain yang berkunjung ke Banjarmasin adalah dalam rangka menyambut kedatangan Sukarjo Wiryopranoto dari Surabaya, Pengurus Besar Parindra merangkap Pemimpin Surya Wirawan pusat, dan R. Sunyoto anggota Parindra yang berkedudukan di Surabaya. Mereka datang secara rutin ke Banjarmasin (Hadhariyah, 1981:8).

Dalam rangka menyambut kedatangan Sukarjo Wiryopranoto dari Surabaya maka pada tahun 1939 Parindra cabang Amuntai mengadakan rapat umum dipimpin Mr.Rusbandi bertempat di gedung Musyawaratutthalibin Amuntai, dihadiri Cabang Parindra, ranting-ranting, serta undangan. Setelah menyanyikan lagu Indonesia Raya oleh para pemuda Surya Wirawan, diadakan pula sambutansambutan oleh Hadhariyah $M$ dari cabang Parindra Banjarmasin, Sukarjo Wiryopranoto dari Pengurus Besar Parindra, dan A. Hamidhan dari cabang Parindra Amuntai (A. Hamidhan, 1981: tanpa halaman).

Setelah kedatangan Mohammad Husni Thamrin dan Sukarjo Wiryopranoto maka tindakan pemerintah kolonial terhadap Parindra menjadi lebih longgar, karena segala yang bersifat pertemuan atau rapat tidak lagi dipersulit atau dilarang dengan catatan, hanya yang bersifat rapat umum harus ada izin dari polisi PID, $2 \mathrm{x}$ 24 jam sebelum rapat dilaksanakan (Darmawie, 1981:6).

Nama Parindra sedemikian populer waktu itu. Di Banjarmasin pada tahun 1939, anggotanya telah mencapai jumlah 10.000 ditandai dengan masuknya anggota Abdullah asal Kuala Kapuas. Para anggotanya terhimpun pula dalam beberapa organisasi bawahannya dan kegiatan seperti Rukun Tani, Koperasi, Rukun Pelayaran Indonesia (Roepelin), Lumbung Padi, Keputrian, Kepanduan Surya Wirawan, maupun Perguruan Rakyat Parindra itu sendiri.

Lumbung Padi adalah sejenis koperasi yang dibentuk pengurus Parindra untuk menunjang ketahanan pangan. Mereka mengajak para petani untuk bergabung dan bergiat untuk mencapai tujuan organisasi (Badrun, tanpa tahun: tanpa halaman).

Menurut Artum Artha (Wajidi, 2007:183) Rukun Puteri dipimpin langsung oleh Ibu-ibu Parindra. Mereka tidak termasuk kelas intelek, bahkan diantaranya tidak punya ijazah Sekolah Rakyat, namun mereka cakap memimpin organisasi politik dan pandai berdebat. Seperti Ibu Haji Saniah yang turut hadir dalam Kongres Parindra di Bandung. Ketika dipersilakan naik mimbar (podium), orang merasa heran dan terbelalak matanya, karena melihat kecakapan Beliau dalam bicara dan berdebat.

Koperasi yang dimiliki Parindra bertujuan untuk meringankan beban rakyat, seperti: koperasi simpan pinjam murni, koperasi pangan, koperasi perkakas sepeda, dan koperasi tukang jahit.

Mengenai Roepelin, usaha pelayaran ini cukup berkembang sehingga maskapai pelayaran Belanda yaitu KPM merasa cemas dan dirugikan. Mereka menghadapi Roepelin dengan memberikan bonus kepada pedagang yang memuat barang dagangan pada kapal KPM.

Roepelin juga seringkali membantu orang-orang pergerakan yang melarikan diri ke Pulau Jawa dan yang masuk kembali ke Pulau Kalimantan dengan membawa bahan-bahan untuk perjuangan rakyat dengan memakai perahu Lete-Lete (Perahu Suku Madura), dan juga perahu Penes (Pinisi) dari Pagatan, Mendawai, Samuda, dan Kuala Pembuang (Badrun, 1985:tanpa halaman).

Menurut Achmad Darmawie (1981:8-9) pengurus Roepelin merupakan orang yang sangat mengetahui seluk beluk 
pelayaran, seperti I.R. Lobu, Pimpinan Roepelin di Banjarmasin, ia seorang ambtenaar dari Bea dan Cukai (Douane) Banjarmasin yang berkantor pusat di Surabaya yang dipimpin oleh Nazamudin Daeng Malewa yang juga menjabat Komisaris Pengurus Besar Parindra.

Akibat besarnya dukungan masyarakat terhadap Roepelin, maka pengurusnya kerapkali berurusan dengan pihak polisi Belanda seperti berupa penggeledahan, penahanan dengan bermacam-macam tuduhan disertai todongan senjata api, berkaitan dengan pengaduan yang disampaikan maskapai KPM yang merupakan milik Pemerintah Hindia Belanda.

Parindra bukan saja berusaha dalam bidang ekonomi dan politik, tetapi juga dalam pendidikan. Hasil karya Parindra dalam pendidikan antara lain membentuk Sekolah atau Perguruan Rakyat Parindra di Banjarmasin, Barabai, Birayang, Amuntai, dan Kandangan.

Di Kandangan, organisasi Parindra mendirikan Badan Pengawas Onderwijs Commissie (BPOG) dan mendirikan Perguruan Medan Antara yang kemudian menjadi Sekolah Medan Antara (SMA Parindra) di Kandangan. Selain itu berdiri pula Taman Antara di Negara dan Sekolah Rakyat (5 tahun) di Kandangan Kota, Karang Jawa, dan Gambah.

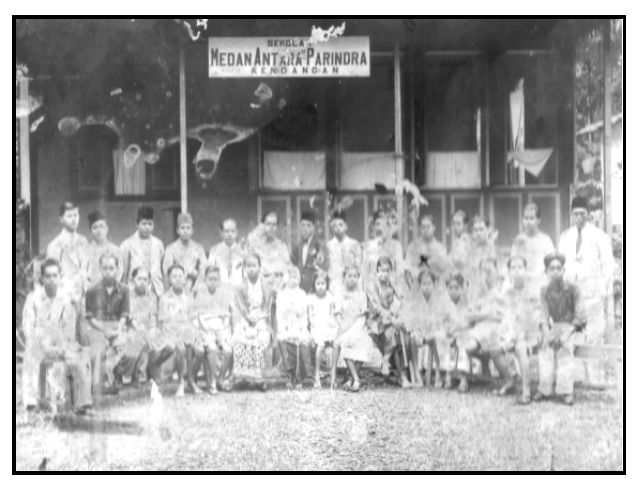

Gambar 6. Pembukaan Sekolah Medan Antara di Kandangan, 15 Juli 1937. Berdiri, Artum Artha (tanda X).

Sumber: Koleksi Artum Artha
Pentingnya pendidikan bagi Parindra tercermin dari pendapat Johanes Baker seorang guru Sekolah Medan Antara Kandangan pada saat peresmian berdirinya sekolah "Perguruan Rakyat Parindra" di Amuntai tanggal 1 Agustus 1935 bahwa: "perguruan adalah satu soal yang sangat penting dan satu alat yang utama. Anakanak tidak dapat maju, kalau tidak dapat didikan" (Soepardi, 1972:20).

Sekolah Perguruan Rakyat Parindra di Kandangan berdiri pada tahun 1937 di Jalan Kubur Wih (kemudian di sebut Jalan Merdeka). Guru-gurunya yakni Raden Imam Subekti (Kepala Sekolah), Johanes Baker (Pembantu) berasal Parindra Surabaya.

Mata pelajaran yang diajarkan adalah bahasa Belanda dan bahasa Inggris, serta pelajaran lainnya yang berhubungan dengan kegiatan sosial, politik, ekonomi dan kebudayaan. Sebagai pemegang vak bahasa Belanda adalah Imam Subekti, sedangan Johanes Baker memegang vak bahasa Inggris yang setelah ditangkap belanda diganti oleh Adi Martono, seorang guru dari Perguruan Taman Siswa (Aly, 1987:2).

Karena sekolah berkembang menjadi dua kelas, maka pengajarnya ditambah yakni Iberamsyah dan Rosita dan kemudian dibantu Abdul Sani, beberapa saat setelah Imam Subekti dan Adi Martono pulang ke Jawa.

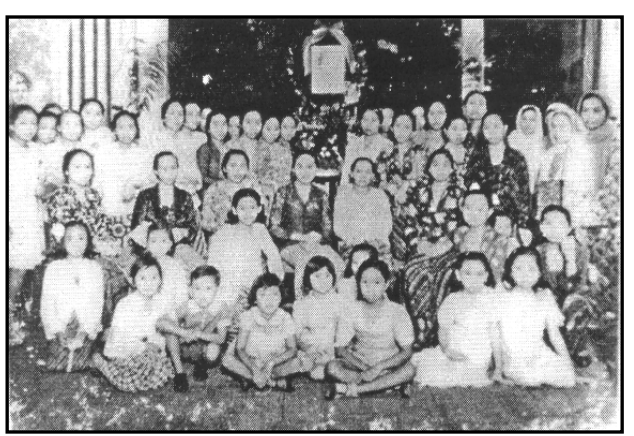

Gambar 7. Rukun Keputrian Parindra di Banjarmasin. Di tengah Gusti Noorsehan Johansyah, dengan latar foto ibu Kartini. Sumber: Koleksi Yurliani Johansyah 
Sekolah Parindra selalu mendapat tekanan dari Pemerintah Hindia Belanda. Jika anak pegawai negeri memasuki sekolah Parindra, maka si ayah yang pegawai negeri kalau tidak dipindahkan bisa pula diberhentikan dari pekerjaannya (Sjarifuddin, 1974: 68).

Besarnya tekanan pemerintah kolonial bukan tanpa alasan, karena melalui sekolah Parindra para kaum pergerakan berupaya menanamkan perasaan kebangsaan dan membentuk kader, antara lain dengan mengajarkan sejarah kebangsaan Indonesia yang berlawanan dengan sejarah Indonesia karangan Belanda. Di samping itu, setiap akan memulai pelajaran terlebih dahulu menyanyikan lagu Indonesia Raya, begitu pula ketika akan pulang, walau redaksinya agak berbeda dengan yang sekarang (Sjarifuddin, loc.cit).

Pada akhir tahun 1939 sekolah Parindra dilebur menjadi IHS (Inheemse Hollandse School). Sesudah peleburan itu maka pengertian Sekolah Perguruan Parindra sudah hilang, dan kembali ke sekolah sejenis Inlandse School (Sekolah Gubernemen kelas dua). Kalau dahulu untuk memasuki sekolah Perguruan Rakyat Parindra harus tamat Inlandse School atau sederajat, maka kemudian sekolah ini setingkat dengan sekolah dasar.

Selain telah didirikannya Sekolah Perguruan Rakyat Parindra yang oleh masyarakat Kandangan lebih dikenal dengan "Taman Medan Antara", juga telah mendirikan sekolah-sekolah sejenis Volkschool tiga tahun. Di Kandangan sekolah-sekolah tersebut terdapat di Karang Jawa, Gambah, Bekarung, dan Tinggiran.

Sekolah Parindra setingkat Volkschool tersebut juga terdapat di Banjarmasin, Barabai, Birayang, dan persiapan di Amuntai. Sedangkan sekolah Perguruan Rakyat yang setingkat dengan MULO hanya ada di Kandangan (Nawawie, ed., 1992: 64-66).
Guru-guru yang mengajar di sekolah tersebut dari anggota Parindra sendiri. Mereka digaji oleh Pengawas Onderwijs Commissie (POC) Parindra. Seorang guru sekolah pada Volkschool Parindra ini mendapat gaji f.7.50 dan bagi guru bantu diberi gaji f.5.00. Di antara pengajar yang merupakan alumni Taman Medan Antara adalah Artum Artha yang diangkat menjadi guru bantu pada Sekolah/ Perguruan Rakyat Parindra di Kandangan (Artha, 1995:1).

Di Barabai, usaha Parindra di bidang pendidikan mengalami kemajuan pesat dengan mendirikan sekolah rakyat Parindra di Bulau, Ilung, Birayang, Rangas, Tapuk, dan Kabang. Sekolah itu pada umumnya menggunakan rumah penduduk sebagai tempat belajar yang menandakan bahwa masyarakat di pedesaan sudah memahami betul artinya gedung sekolah dan perlunya pendidikan. Akan tetapi, kemajuan itu tidak serta merta diperoleh dengan mudah. Seperti yang terjadi di Desa Tapuk dan Kabang. Para pengurus dan guru-guru Parindra harus menghadapi hambatan-hambatan yang cukup pahit, ketika memperjuangkan sekolah Parindra di desa itu.

\section{Tindakan Pemerintah Hindia Belanda terhadap Parindra}

Parindra merupakan organisasi yang melaksanakan prinsip cooperatie terhadap Pemerintah Hindia Belanda. Karena prinsip itulah, maka wakilwakilnya dapat duduk dalam dewan provinsi, kabupaten maupun pemerintahan kota. Akan tetapi, perasaan cemas dan takut muncul di pihak pemerintah setelah melihat aktivitas Parindra yang cenderung melawan pemerintah kolonial. Oleh karena itu, Pemerintah Hindia Belanda selalu menempatkan orang atau polisi PID di setiap rapat partai, baik rapat terbuka maupun rapat tertutup. Tidak jarang PID ini mencari-cari alasan atau perkara untuk membubarkan rapat Parindra, dan menawarkan bantuan berupa uang kepada 
pengurus Parindra agar mau memberikan laporan atau rahasia kepartaian.

Mara Aly (1987:3), seorang anggota Parindra atau guru Sekolah Parindra di Kandangan, menceritakan:

Pernah beberapa kali PID datang ke rumah saya membujuk dan menawarkan bantuan f.30 setiap bulan dan bisa naik menjadi f.75 setiap bulannya asalkan saya mau memberikan laporan-laporan kepartaian urusan dalam. Setiap kali tawaran itu, setiap kali pula saya tolak meskipun pada waktu itu gaji saya hanya f.5 sebulan menjadi guru sekolah swasta dengan tanggungan 1 orang isteri, 3 orang anak, 1 orang tua serta 1 orang saudara yang cacat.

Seperti rapat Parindra tahun 1939. Rapat ini dibubarkan dan pembicaranya yakni H. Ali Baderun, Ketua Parindra cabang Barabai ditangkap dan oleh Landraad (pengadilan) Kandangan yang bersidang di Barabai, yang bersangkutan dijatuhi hukuman 2 tahun penjara, meski terhukum kemudian mengajukan banding ke Pengadilan Negeri Surabaya.

Belanda juga melihat bahwa aktivitas Merah Johansyah selaku Komisaris Pengurus Besar Parindra akan membahayakan kedudukan pemerintahannya. Oleh karena itu pada tahun 1937 pemerintah kolonial memaksa Merah Johansyah dan keluarga untuk pindah ke Surabaya. Akan tetapi, di Surabaya, Merah Johansyah dan isterinya Gusti Noorsehan Johansyah tetap aktif di Organisasi Parindra. Pada tahun 1939 ia diizinkan kembali pulang ke Banjarmasin. Meski kondisi kesehatannya memburuk, Merah Johansyah tetap beraktivitas di daerah ini sampai ia meninggal karena sakit di Kandangan pada tanggal 8 April 1942 (Aziddin, 1986/1987:6).

Surya Wirawan merupakan organisasi kepemudaan terpenting yang dikelola Parindra. Melalui Surya Wirawan dibentuk kader-kader muda yang suatu saat akan menjadi Parindrist guna memajukan Organisasi Parindra.

Dalam rangka menyambut Kongres Parindra ke-3 di Banjarmasin, maka Surya Wirawan turut mempersiapkan diri untuk terlibat dalam kongres tersebut dengan terlebih dahulu mengadakan Konferensi Surya Wirawan ke-III se Kalimantan Selatan di Barabai tanggal 9 April 1939. Konferensi itu dipimpin langsung oleh Hadhariyah M, pengganti Merah Johansyah selaku Komisaris Pengurus Besar Parindra daerah Kalimantan Selatan dan Timur. Konferensi berlangsung lancar meski mendapat pengawasan ketat dari PID. Pada saat konferensi berlangsung, tersiar kabar bahwa Ki Hajar Dewantara, tokoh Pimpinan Umum Majelis Luhur Taman Siswa segera tiba di Banjarmasin. Hadhariyah $M$ yang saat itu ingin segera kembali ke Banjarmasin untuk menjemput Ki Hajar Dewantara, dihalangi dan dicegat PID di Kandangan (Hadhariyah, 1981:8).

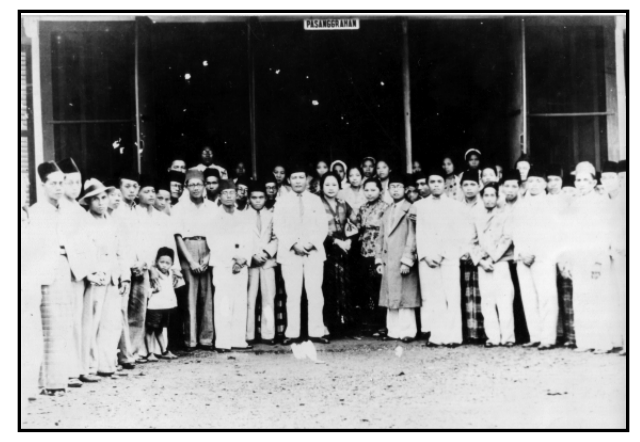

Gambar 8. Kunjungan Muhammad Husni

Thamrin (Ketua Pengurus Besar Parindra) di Pesanggrahan Kandangan tahun 1938. Sumber: Koleksi Achmad Darmawie.

Sesuai agenda, Kongres Parindra ke3 akan dilaksanakan pada tanggal 10-12 Mei 1940 bertempat di Gedung Bioskop Eldorado, Pasar Lama Banjarmasin. Kongres ini dihadiri cabang-cabang Parindra di Kalimantan Selatan. Sebelum puncak acara (kongres) dilaksanakan, terlebih dahulu diadakan rapat umum yang dilaksanakan pada malam hari di Gedung Bioskop Eldorado. Selain dihadiri anggota Parindra, Surya Wirawan, rapat umum itu 
juga dihadiri oleh polisi PID, Wedana, dan Komisaris Polisi untuk Kalimantan, di samping banyaknya pengunjung sehingga penuh sesak sampai ke luar gedung.

Pada saat rapat umum berlangsung terjadilah kericuhan, karena utusan Parindra cabang Amuntai dengan beraninya mengibarkan bendera Merah Putih meski berdampingan dengan bendera Belanda pada saat arak-arakan. Begitupula A. Zakaria, salah seorang tokoh Parindra Banjarmasin, dengan bersemangat berbicara mengobarkan semangat kemerdekaan.

Achmad Darmawie (1981: 9) yang turut hadir dalam rapat umum di gedung Eldorado, menceritakan bahwa A. Zakaria mengucapkan: “.....bagaimana juapun air itu dibendung suatu ketika bendungan itu akan hancur lebur.....".

Pada saat itulah, Komisaris Polisi van Burer dari PID berteriak:

“... stop turun! Maka Zakaria turun dari podium. Dan atas perintah komisaris rapat dibubarkan dan semua hadirin supaya meninggalkan Gedung Eldorado. Di sekeliling gedung telah diblokir oleh polisi dengan lengkap alat senjata senapan.....

Setelah kejadian itulah maka Zakaria dan sekalian pengurus Parindra yang ada dalam kepanitiaan kongres ditahan polisi PID, ditanyai tentang apa maksud pembicara tersebut. Pihak Belanda menyatakan bahwa pembicaraan Ketua Panitia Kongres Parindra saat berpidato di podium dianggap telah melanggar peraturan Wetboek van Straftrecht Nederlandsche Indie (Artha, 1995:1-2). Oleh Pemerintah Hindia Belanda A. Zakaria dipersona-nongratakan di Kalimantan Selatan dan akhirnya dipindahkan ke Malang.

Para utusan Parindra dari Kandangan juga mengalami nasib yang sama, karena setelah mereka pulang kembali di Kandangan mereka ditangkap oleh pemerintah kolonial dan dimasukkan ke penjara selama 6 (enam) bulan, karena dituduh selama di Banjarmasin telah mengadakan rapat gelap di dalam kamar Hotel Simpang Banjarmasin (Bijuri, 1980: tanpa halaman).

Adakalanya tekanan terhadap anggota Parindra justru datang dari seorang pribumi pejabat tinggi pemerintah. Memang, seringkali ada bangsa pribumi (Indonesia) yang ambtenaar Binnenlands Bestuur lebih keras memberi tindakannya, apalagi jika dia Inspektur Polisi, Resersi Klas I/II atau dia punya pangkat/jabatan Komis Kepala (Hoofd Commies), betapa congkaknya, sungguh berani mengejek bangsanya sendiri. Seperti yang diceritakan oleh Artum Artha (Wajidi, 2007:191), bahwa sekitar tahun 1932 dan tahun 1938, Beliau pernah mengalami dan merasakan cubit-cercaan:

"He, Tum. Kalau mau merdeka, bikin dulu benang katon. Pandai jahit dengan jarum. Pandaikah membuat jarum sebilah dalam setahun?". "Nah, ayo, coba-coba merdeka".

Lebih lanjut Artum Artha menceritakan bahwa sekitar tahun 1938 juga pernah mendapatkan cercaan dari seorang pejabat yang sangat dikenal di Kalimantan Selatan, yakni seorang Kiai Kepala (Districthoofd) Kandangan Kota bernama Kiai Merah Nadalsyah. Kepada Artum, Kiai Kepala itu berkata:

"Heh, Tum. Kau serdadunya Parindra. Kapan Parindra merdeka, pabila (kapan, pen) ada pabrik jarum dan kain kaki drill. Sampai kiamat Belanda tidak menyuruh merdeka. Pikirkan: Lekas pulang: Laporkan kepada Guru-Guru politik".

Tindakan keras juga dikenakan terhadap tokoh Parindra cabang Kandangan, H. Ahmad Barmawi Thaib, lantaran sering menulis artikel yang bersifat politik melalui mingguan Pembangunan Semangat. Beliau dituduh persdelict (tulisan yang dianggap menentang atau menghasut terhadap pemerintah sehingga dapat dituntut hukuman di pengadilan) dan dijatuhi 
hukuman penjara 3 tahun oleh Landraad Kandangan. Upaya Mr. Rusbandi, yakni Komisaris Daerah Parindra Kalimantan Selatan yang sekaligus sebagai pembela tidak berhasil meyakinkan hakim kolonial, sehingga $\mathrm{H}$. Ahmad Barmawi dikirim ke penjara Sukamiskin di Jawa Barat.

Parindra cabang Amuntai juga mendapat cobaan hebat setelah pimpinannya membuat mosi menentang peraturan kerja erakan (rodi). Mereka adalah yakni $\mathrm{H}$. Murhan dijatuhi hukuman penjara 2 tahun 6 bulan dan Abdul Hamidhan 1 tahun yang dikerjapaksakan di Penjara Ampah, sedangkan H. Amir dan Edwar Sandan masing-masing dikenakan penjara 2 tahun dan dikirim ke penjara Sukamiskin. Para tertuduh dalam persidangan dibela oleh Mr. Iskak, Mr. Rusbandi, dan Mr. Tajudin Noor.

Menurut Aam Niu, dalam tulisannya di Banjarmasin Post, 8 Desember 1978, peristiwa itu bermula dari adanya rapat umum Rukun Tani dan Rukun Kampung, organisasi rakyat dibawah Parindra untuk menolak pengenaan pajak Heeren Dienst terutama bagi orang yang sudah berumur 45 tahun ke atas, dan juga memperjuangkan agar peraturan yang sangat memberatkan rakyat itu dicabut keseluruhannya yang ditanggapi Belanda dengan melakukan penangkapan terhadap berpuluh-puluh anggota Parindra. Ketika itulah, Panitia Pertahanan Rakyat Amuntai yang dibentuk Parindra dipimpin oleh $\mathrm{H}$. Amir dan Edwar Sandan melancarkan demonstrasi ke Kantor Controleur menuntut pembebasan rekan mereka. Peristiwa yang terjadi tanggal 22 Juni 1939 itu dianggap pemerintah sebagai usaha untuk memberontak.

Lebih lanjut Aam Niu menulis tentang Edwar Sandan dalam Dinamika Berita, 24 November 1984. Menurutnya, Edwar Sandan adalah kepala sekolah Vervolgschool di Amuntai. Sebagian besar gajinya habis untuk kepentingan perjuangan, dan hanya sebagian kecil untuk keluarga. Karena itu tak mengherankan, kalau ia merokok dengan mempergunakan daun pisang kering (kelaras/keraras) buat menggulung tembakaunya, dan terkadang dengan pipa. Ketika mendengar Edwar Sandan akan dikirim ke penjara Sukamiskin, isterinya yang hamil tua menyusul ke Banjarmasin menumpang kapal sungai. Setelah kembali ke rumahnya di Tangga Ulin, ia meninggal dunia setelah melahirkan anaknya. Karena penderitaan hidup yang tak tertahankan, puteri sulungnya menderita sakit jiwa sehingga tidak dapat meneruskan merawat adik-adiknya yang masih kecil itu. Sementara itu, diberitakan pula Edwar Sandan telah meninggal dunia dalam masa menjalani hukumannya di Penjara Sukamiskin, Jawa Barat.

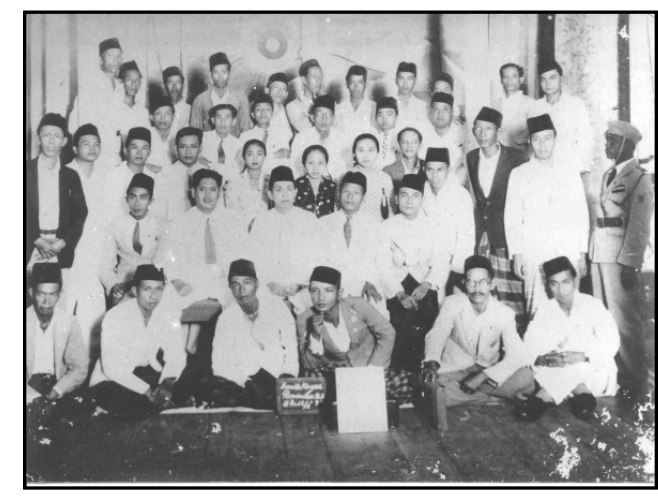

Gambar 9. Rapat panitia Kongres Parindra ke-3 di Banjarmasin, 4/5 Februari 1940. Baris kedua, dari kiri ke kanan: Hadhariyah M Penulis

II, Dokter R. Sosodoro Jatikusumo Wakil

Ketua, Merah Johansyah Ketua, Sumarno Bendahara, Mr. Rusbandi Penulis I.

Sumber: Koleksi Yurliani Johansyah.

Nasib serupa juga dialami oleh Ketua Cabang Parindra Banjarmasin Hadhariyah M, ia telah menjadi korban delik bicara dalam suatu rapat umum Parindra di Barabai dengan tuntutan melanggar pasal 151 bis dari Wetboek van Strafrecht pemerintah Hindia Belanda. Judul pembicaraan Hadhariyah adalah karena menghimbau "Burung Dalam Sangkar Mas" dan membahas bahwa belanja hidup seekor anjing yang ditangkap dan dikurung oleh polisi 
Belanda di Surabaya karena tanpa penning adalah sebesar f. 50 sehari yang kelak harus dibayar oleh sang punya anjing itu. Sedangkan belanja hidup seorang rakyat Indonesia, cukup sebenggol atau 2,5 sen sehari. Bayangkan kata Hadhariyah M, betapa ambruk martabat hidup dan betapa miskinnya rakyat Indonesia di Hindia Belanda. Di tanah airnya sendiri, karena ucapannya itu, ditangkaplah Hadhariyah M. dan diganjar hukuman penjara selama 3 bulan dan membayar denda f. 100 (Hadhariyah, 1981:9).

Lebih lanjut Hadhariyah $\mathrm{M}$. menceritakan bahwa pada saat Hadhariyah $M$. ingin berangkat ke Surabaya untuk menghadiri Konferensi Besar Parindra di Surabaya, maka pada tanggal 17 Juni 1941 dalam kesibukan persiapan keberangkatan, ia ditangkap dan didakwa melanggar pasalpasal 156, 157, dan 193 bis/ter Wetboek van Straafrecht (KUHP).

Pelanggaran itu terjadi, karena Hadhariyah M. telah menulis sebuah roman politik yang berjudul "Suasana Kalimantan" dan diterbitkan di Medan dengan judul "Tersungkur Di Bawah Kaki Ibu". Tulisan itu dianggap pemerintah bertendensi politik dan melakukan persdelict sehingga penulisnya bersama penanggung jawabnya, diajukan ke pengadilan Banjarmasin. Dalam sidang pengadilan (landraad) pada bulan November 1941, hakim kolonial menjatuhi vonis 4 tahun penjara kepada Hadhariyah M. dan 1,5 tahun penjara kepada Matu Mona. Tepatnya pada tanggal 1 Februari 1942 Hadhariyah M. menjalani kehidupan penjara, setelah upaya naik bandingnya ditolak oleh Raad van Justitie di Surabaya. Berdasarkan informasi yang diterima Hadhariyah $M$ dari seorang kerabatnya yang bekerja dalam Geheime Dienst Pemerintah Hindia Belanda, bahwa Penguasa Tinggi Pemerintah di Banjarmasin menilai Hadhariyah $\mathrm{M}$. sebagai seorang "hollander hater" (pembenci Belanda) dalam tulisan-tulisan politiknya (Hadhariyah M., 1981:6 dan $10)$.
Adapula semacam rintangan yang disebut dengan istilah "Spionase Konyol". Spion yang kadangkala orangnya buta huruf, sering mengintip rapat rapat atau kursus-kursus Parindra dan melaporkan kepada tuannya. Akibat laporan itu, si pembicara sudah berhadapan dengan polisi atau HPB (Hoofd van Plaatselijk Bestuur). Peristiwa semacam itu, sering menghalangi kegiatan Parindra (Saleh dkk., 1978/1979:109-112).

Para pengurus dan guru-guru Parindra juga mengalami perlakuan yang sama dan harus menghadapi hambatan-hambatan yang cukup pahit dalam memperjuangkan berdirinya sekolah Parindra sebagaimana yang terjadi di Tapuk dan Kabang. Barabai. Karena dianggap membangkang terhadap Tuan Asisten Kiai yang melarang pendirian sekolah, maka ketua POC cabang Parindra Birayang $H$. Busri, dihukum 20 hari atau denda f.20 karena meneruskan pembukaan sekolah rakyat di Tapuk dan Kabang. Guru sekolah di Tapuk, H. Asmuni dihukum 10 hari atau denda f.10, dan Abdul Muis guru di Kabang dikenai hukuman 5 hari atau denda f.10 (Busri, tanpa tahun:tanpa halaman) .

Terkait dengan tindakan Pemerintah Hindia Belanda terhadap kaum pergerakan tidak terlepas dari aturan yang pemerintah buat untuk mengatur kehidupan politik di Hindia Belanda. Semula berdasarkan R.R. (Regerings Reglement) 111 Staatsblad 1885 No. 2 pemerintah melarang perkumpulan dan rapat-rapat politik, namun kemudian mengeluarkan peraturan lainnya yakni Staatsblad 1915 No. 215 R.R. 111 yang membolehkannya. Namun dalam pelaksanaannya, hak ini diatur dan dibatasi dengan peraturan-peraturan. Seperti pada Staatsblad 1919 No. 27 jo 561 Pasal 1 berbunyi: (1) Untuk mendirikan perkumpulan-perkumpulan tidak diperlukan izin pemerintah; (2) Seseorang boleh menjadi anggota partai politik jika telah berumur 18 tahun. Pasal 5 berbunyi: "Untuk mengadakan rapat umum diperlukan izin pemerintah" (Yayasan 
Gedung-Gedung Bersejarah Jakarta, 1974: 14-15).

Selain itu Pemerintah Hindia Belanda memiliki KUHP yang di dalamnya terdapat beberapa "pasal karet" karena mempunyai konotasi arti dari perkataan-perkataan yang dipergunakan tidak mengandung makna pasti tetapi bersifat elastis sehingga dapat diterapkan sesuai dengan makna yang dikehendaki oleh penguasa guna mengatasi pelbagai kasus yang merugikan atau mengancam sistem kolonial. Pasal-pasal dimaksud di antaranya: Pasal 153 bis; Pasal 153 ter; Pasal 161 bis; dan Pasal 171 bis (Wajidi, 2007:195).

Pasal 153 bis berbunyi:

"Barang siapa dengan perkataan, tulisan atau gambar melahirkan pikirannya yang biarpun secara menyindir atau samar-samar, memuat anjuran untuk mengganggu keamanan umum atau menentang kekuasaan Pemerintah Nederland atau Pemerintah Hindia Belanda dapat dihukum penjara maksimum 6 tahun atau denda maksimum Rp 300,00". Perkataan-perkataan yang bersifat karet pada pasal itu, yaitu 'menyindir', 'samar-samar' dan 'mengganggu keamanan umum'.

Pasal 153 bis sifat karetnya sama dengan isi pasal 153 ter yang berbunyi:

"Barangsiapa menyiarkan,
mempertunjukkan atau
menempelkan tulisan atau gambar
yang memuat pikiran seperti
dimaksud dalam pasal 153 bis dapat
dihukum penjara maksimum 5 tahun
atau denda maksimum Rp 300,00".

Pasal 153 tersebut seringkali khusus ditujukan pada para penanggungjawab media massa (termasuk redaktur) yang tidak menyebutkan nama penulis atau samaran.

\section{PEN UTUP}

Berdasarkan tujuan dan pembahasan yang telah dipaparkan dapat disimpulkan bahwa asal mula Parindra di
Kalimantan Selatan adalah organisasi Persatuan Bangsa Indonesia (PBI) yang berfusi dengan Budi Utomo dan organisasi lainnya di Pulau Jawa menjadi Partai Indonesia Raya (Parindra) di tahun 1935. Akibat dari fusi itu maka PBI di Kalimantan Selatan menjadi Parindra.

Dalam perjuangannya, organisasi Parindra melaksanakan prinsip kooperatif sebagai sebuah strategi agar wakilwakilnya dapat duduk dan berjuang dalam dewan legislatif (Raad) di tingkat provinsi, kabupaten maupun pemerintahan kota.

Perjuangan Parindra di Kalimantan Selatan di antaranya: mendirikan Rukun Tani, Koperasi, Rukun Pelayaran Indonesia (Roepelin), Lumbung Padi, Keputrian, Kepanduan Surya Wirawan, Sekolah Parindra, menulis artikel politik dan mengeluarkan mosi menentang peraturan kerja paksa (erakan, rodi).

Meski menganut prinsip kooperatif, aparat pemerintah kemudian merasa cemas setelah melihat aktivitas Parindra yang cenderung melawan pemerintah kolonial. Oleh karena itu, Pemerintah Hindia Belanda melakukan tindakan dengan cara menempatkan orang atau polisi PID untuk melakukan pengawasan di setiap rapat partai, baik rapat terbuka maupun rapat tertutup. Tindakan lainnya adalah membubarkan rapat Parindra, dan menawarkan bantuan berupa uang kepada pengurus Parindra agar mau memberikan laporan atau rahasia kepartaian.

Selain itu, Pemerintah Hindia Belanda menerapkan peraturan pelarangan melakukan perkumpulan dan rapat-rapat umum, namun kemudian membolehkannya disertai dengan pengaturan yang ketat untuk membatasi dan bahkan membubarkan perkumpulan atau rapat yang dianggap membahayakan pemerintah. Dengan penerapan "pasal karet", pemerintah Hindia Belanda bahkan melakukan penangkapan dan pemenjaraan aktivis Parindra baik pengurus organisasi, wartawan maupun guru-guru Parindra dengan penerapan aturan kerja paksa di penjara Kalimantan Selatan atau 
memenjarakannya di beberapa penjara di Pulau Jawa.

\section{DAFTAR SUMBER}

\section{Skripsi}

Sjarifuddin. 1974.

"Sikap Pergerakan Rakyat Menghadapi Pendudukan Belanda di Kalimantan Selatan Periode 1945 sampai dengan 17 Agustus 1950”. Banjarmasin: Skripsi Sarjana Pendidikan Jurusan Sejarah FKg Unlam.

Soepardi. 1972.

"Sejarah Singkat Pertumbuhan dan Perjuangan Dari: Partai Nasional Indonesia, Pendidikan Nasional Indonesia, Gerakan Rakyat Indonesia, di Kalimantan Selatan". Banjarmasin: Skripsi Sarjana Muda Pendidikan Jurusan Sejarah FKg Unlam.

\section{Buku}

Abdullah, Taufik (ed.). 2013.

Sejarah Pemikiran Indonesia Modern. Jakarta: Direktorat Sejarah dan Nilai Budaya. Direktorat Jenderal Kebudayaan Kemdikbud.

Arsip Nasional Republik Indonesia. 1996. Inventaris Arsip Borneo. Jakarta.

Gottschalk, Louis. 1985.

Mengerti Sejarah. Terjemahan Nugroho Notosusanto. Cetakan 4. Jakarta: Penerbit Universitas Indonesia (UIPress).

Nawawi, Ramli (ed). 1992.

Sejarah Pendidikan Daerah Kalimantan Selatan. Banjarmasin: Bagian Proyek Penelitian Pengkajian dan Pembinaan Nilai Budaya Kalimantan Selatan.

Pemda Tk. I Kalsel. 1990.

Sejarah Perjuangan Rakyat Menegakkan Kemerdekaan Kemerdekaan Republik Indonesia di Kalimantan Selatan (Periode 19451949). Banjarmasin.

Saleh, M. Idwar et al. 1978/1979. Sejarah Daerah Tematis Zaman Kebangkitan Nasional (1900-1942) di Kalimantan Selatan. Banjarmasin:
Proyek Penelitian dan Pencatatan Kebudayaan Daerah Depdikbud.

Scherer, Savitri Prastiti. 1985.

Keselarasan dan Kejanggalan: Pemikiran-pemikiran Priayi Nasionalis Jawa Awal Abad XX. Jakarta: Sinar Harapan.

Sitorus, L.M. 1951.

Sedjarah Pergerakan Kebangsaan Indonesia. Jakarta: Pustaka Rakjat N.V.

Sjamsuddin, Helius, 2012.

Metodologi Sejarah. Yogyakarta: Penerbit Ombak.

Wajidi. 2007.

Nasionalisme Indonesia di Kalimantan Selatan. Banjarmasin: Pustaka Banua.

Yayasan Gedung-Gedung Bersejarah Jakarta. 1974.

45 Tahun Sumpah Pemuda. Jakarta: Gunung Agung.

\section{Surat Kabar, Memoar, dan Manuskrip}

Alibasah. 1981.

Riwayat Perjuangan H. Alibasah. (Naskah Ketikan. )Martapura.

Aly, Mara. 1987.

Riwayat Perjuangan Mara Aly (Naskah Ketikan). Kandangan.

Arief, Mohammad Nawawie. 1981.

Sepak Terjang Haji Mohammad Nawawie Arief Dalam Perjuangan (Naskah Ketikan). Banjarmasin.

Artha, Artum. 1984.

Cita-Cita Mencapai Indonesia Mulia Merdeka dan Berdaulat (Naskah Ketikan). Banjarmasin.

Artha, Artum. 1995.

Mencapai Usia Lanjut 75 Tahun (Naskah Ketikan). Banjarmasin.

Badrun, Mohammad Ali. Tanpa tahun. Riwayat Singkat Perjuangan Mohammad Ali Badrun bin Usman (Naskah Ketikan). tt.

Badrun, Mohammad Ali. 1985.

Riwayat Perjuangan Singkat
Muhammad Ali Badrun bin Usman
(Naskah Ketikan). Banjarmasin.

Bijuri. 1980. 
Ringkasan Riwayat Perjuangan Bijuri bin H. Saleh (Naskah Ketikan). Kandangan.

Busri, H. Tanpa tahun.

Riwayat Perjuangan H. Busri bin $H$. Abdul Hamid (Naskah Ketikan). tt.

Darmawie, Achmad. 1981.

Detik-Detik Perjuangan Kemerdekaan di Banjarmasin Kalimantan Selatan (Naskah Ketikan). Banjarmasin.

Duraup, Aban. 1983.

Riwayat Singkat Perjuangan Aban Duraup Dalam Rangka Perjuangan Kemerdekaan Indonesia di Kalimantan Selatan (Naskah Ketikan). UlinBanjarbaru.

Hadhariyah M. 1981.

Periode-periode Perjuangan di Indonesia yang Saya Alami (Naskah Ketikan). Banjarmasin.

Hamidhan. 1981.

Riwayat Hidup/Riwayat Perjuangan Hamidhan-Juhri (Naskah Ketikan). Haruai.

Niu, Aam.

"Perjoangan Tempoe Doeloe; Kepala Sekolah Vervolgshool Merokok Dengan Kelaras", dalam Banjarmasin Post, 8 Desember 1978.

Niu, Aam.

"Perjoangan Tempoe Doeloe, Kepala

Sekolah Vervolgschool Merokok

Dengan Kelaras", dalam Banjarmasin

Post, 8 Desember 1978.

Niu, Aam.

"Kisah-kisah Perjuangan Heroik, Edwar Sandan Meninggal di Penjara Sukamiskin", dalam Dinamika Berita, 24 November 1984.

Soeara Parindra, Edisi Maret/November (?) 1940.

Uhuk, Abdul Manap. 1981. Riwayat Perintis Kemerdekaan (Naskah Ketikan). Barabai. 